\title{
Identification and Molecular Interaction studies of Thyroid Hormone Receptor Disruptors among Household Dust
}

\section{Contaminants}

Jin Zhang ${ }^{\dagger, 1}$, Yaozong Lit, ${ }^{\dagger, 1}$, Arun A.Gupta ${ }^{\dagger}$, Kwangho Nam ${ }^{\dagger, *}$, Patrik L. Andersson ${ }^{\dagger, *}$

†Department of Chemistry, Umeå University, SE-901 87 Umeå, Sweden.

\section{Corresponding Authors}

*Email: patrik.andersson@umu.se. Tel: +46-90-786-5266

*Email: kwangho.nam@umu.se. Tel: +46-90-786-6570

\section{Author Contributions}

${ }^{1}$ J.Z. and Y.L. contributed equally to this work. 
The supporting information (29 pages) contains the following sections:

Contents

Page No

Ligand parameters generation and optimization

Analyses of MD trajectories

Explanations for differences in binding affinities

S5

Table S1. Information of the seven THR $\beta 1$ X-ray structures

Table S2. Results of molecular docking under the standard precision using single structures

Table S3. Results of the best ensemble models

Table S4. Results of the single best structure docking, the 'best' ensemble model docking, and the MM-GBSA rescoring of the 'best' ensemble model

Table S5. Interactions of the refined hit with the four key hydrophilic residues

Table S6. Information of the dust contaminants tested by ITC

Table S7. The docking scores of different protonation forms of BADGE-HCl-H2O.

Table S8. The state penalties and docking score of different protonation forms of triclosan.

Table S9. Thermodynamic parameters of the four active compounds and T3 binding to THR $\beta 1$.

Table S10. Optimized angle force field parameters

Table S11. Optimized dihedral parameters

Table S12. Optimized improper angle parameters

Figure S1. The ROC curves of molecular docking and MM-GBSA rescoring results of the 'best' ensemble model

Figure S2. Docking poses and ligand-THR interactions of THR disrupters and co-crystallized pose of T3

Figure S3. Correlations between ITC measured binding free energy of the bioactive compounds and their docking and MM-GBSA scores.

Figure S4. Partial atomic charges 2,4,5-T, BP2, and BADGE-HCl-H2O

Figure S5. RMSDs of THR $\beta 1$ LBD backbone and the ligands

Figure S6. Interactions between 2,4,5-T and THR $\beta 1$ binding pocket residues

S10-S11

$\mathrm{S} 12$

$\mathrm{S} 13$

$\mathrm{S} 14$

S15

$\mathrm{S} 16$

$\mathrm{S} 17$

$\mathrm{S} 18$

S19

Figure S7. Distributions of the two rotatable dihedral angels for the ligands

S20

Figure S8. Structural superposition of 15 THR $\beta 1$ LBD crystal structures

References

$\mathrm{S} 22-\mathrm{S} 23$

S24

S25

S26

S27

S28-S39 
Ligand parameter generation and optimization. Initial parameters of the three dust compounds (BP2, 2,4,5T, and BADGE-HCl-H2O) were generated by the CGenFF program (https://cgenff.paramchem.org/). ${ }^{1,2}$ The partial charges and the angle/dihedral/improper angles parameters with the penalty values larger than 10 were optimized against the reference density functional theory (DFT) data determined at the B3LYP/6-31+G(d) level of theory. All DFT calculations were performed using the Gaussian 09 suite of programs. The angle and the improper torsional parameters were obtained directly from the B3LYP potential energy surface around the fully optimized structure of each compound. To determine the dihedral parameters, a scan of potential energy was performed for each dihedral angle to be optimized using the B3LYP level of theory. The MM dihedral parameters were then adjusted manually to best reproduce the DFT results. The optimized parameters are presented in Figures S6 and Tables S8-10. All other parameters not listed in Tables S8-10 were the same as the CGenFF36 force field parameters. ${ }^{1,2}$

For atomic charges, only few atoms were with penalty $>10$. Those atomic charges were determined by the following procedure. First, we have decomposed each target molecule into several (small) model compounds, for example, by replacing functional groups that are remote from a given atomic site to be optimized to either methyl or hydrogen atoms. Those model compounds were designed such that the CGenFF program produced their charges without high penalty. Then, full geometry optimizations were performed for each molecule at the B3LYP/6-31+G(d) level of theory, and their $\mathrm{CHelpG}^{3}$ and $\mathrm{NBO}$ charges were determined in water using the PCM solvation model. ${ }^{4}$ The same calculations were carried out for the target molecules to determine how much their charges would be perturbed between the actual target molecule and each model compound. In this analysis, we found that the $\mathrm{CHelG}$ charges were more systematic and thus used in the charge determination. Finally, the perturbed amount of charge was added to each atom of the model compound, and after partial adjustment of their charges to reproduce the total charge of target molecules, the final atomic charges were determined. In the final step, we also considered the partial atomic charges of the OPLS force field generated by the Maestro interface of the Schrödinger suite of programs, to determine the range of charge perturbation between the model compounds and the target molecules. 
Analyses of MD trajectories. During the 50 ns MD simulation, atomic coordinates were saved at every 2 ps intervals for their analysis. The comparison of RMSD fluctuations of the apo and holo systems showed that ligand binding reduces the RMSD fluctuation of THR $\beta 1$ LBD. Whereas the backbone RMSD of the apo system has increased slowly from $1.1 \AA$ around $1 \mathrm{~ns}$ to $2.1 \AA$ near the $50 \mathrm{~ns}$, the three holo systems showed relatively low and stable RMSD values (mostly below $2 \AA$ ) during the entire 50 ns MD simulations (Figure S7A).

Whereas all three ligands displayed relatively large RMSD fluctuations (Figure S7B), which are mainly due to the small size of the ligands, two ligands (i.e., BP2 and BADGE-HCl-H2O) showed large RMSD values (Figure S7B) compared to their protein backbone RMSDs. Our analysis suggested that the large RMSDs are caused by the rotation of the two benzene moieties of BP2 and BADGE-HCl-H2O relative to each other during MD simulations. In Figure S5, we present the distribution of the two rotable dihedral angles for BP2 and BADGE-HCl-H2O. The distribution shows clearly two well-resolved stable conformations. Nevertheless, they bound stably in the binding pocket of THR $\beta 1$ during the entire 50 ns MD simulations, despite their orientations slightly displaced relative to their corresponding docking poses (Figures 3B and C).

For 2,4,5-T, the salt bridges between Arg282 and Arg320 with the ligand's carboxyl group were maintained during the $50 \mathrm{~ns}$ MD simulation. The comparison of 16 THR $\beta 1$ crystal structures in complex with different coligands showed that the salt bridge interaction with Arg282 is found in 13 structures (Figure S8), suggesting the importance of the electrostatic interaction with Arg282 for the specificity of negatively charged ligands, such as $2,4,5-\mathrm{T}^{5}$ 
Explanations for differences in binding affinities. It has been observed that the affinity of T3 for TR differs between different assays. This could be due to that the monomer of THR was used for the ITC measurement, ${ }^{6}$ whereas the radio ligand binding assay uses the dimeric form. ${ }^{7} \mathrm{~T} 3$ has shown a lower affinity to the monomer as compared with the dimeric form. ${ }^{6,8}$ Secondly, only the ligand binding domain (LBD) of THR was used in our ITC experiments. The T3 binding affinity measured using the truncated system (i.e., LBD without the DNA binding domain and the thyroid response elements) has been reported to be lower than that collected from the complete system. ${ }^{6}$ Although ITC has a relatively lower sensitivity, there are advantages of using ITC; for instance, the costly recombinant baculovirus expression system ${ }^{9}$ was replaced with commonly used Escherichia coli host cell. In addition, we avoided aggregation of the protein by introducing a reducing agent. 
Table S1. Information of the seven THR $\beta 1$ X-ray structures used in the present virtual docking model development.

\begin{tabular}{|c|c|c|}
\hline PDB ID & Resolutions $(\AA)$ & Co-ligand \\
\hline $1 \mathrm{~N} 46$ & 2.20 & [4-(4-Hydroxy-3-isopropyl-phenoxy)-3,5-dimethyl-phenyl]-6-azauracil $^{10}$ \\
\hline 1NAX & 2.70 & 3,5-Dichloro-4-[4-hydroxy-3-(propan-2-yl)phenoxy]phenyl acetic acid ${ }^{\top}$ \\
\hline 1Q4X & 2.80 & [4-(3-Benzyl-4-hydroxybenzyl)-3,5-dimethylphenoxy]acetic acid ${ }^{11}$ \\
\hline $1 \mathrm{R} 6 \mathrm{G}$ & 3.00 & $\begin{array}{l}\text { 2-[3,5-Dibromo-4-(4-hydroxy-3-hydroxy[(2-phenylethyl)amino]methyl } \\
\text { phenoxy)phenyl]ethane-1,1-diol }\end{array}$ \\
\hline $1 \mathrm{XZX}$ & 2.50 & $3,5,3^{\prime}$-Triiodothyronine $\mathrm{s}^{13}$ \\
\hline $2 \mathrm{~J} 4 \mathrm{~A}$ & 2.20 & 3,5-Dibromo-4-(3-isopropyl-phenoxy)benzoic acid ${ }^{14}$ \\
\hline 3IMY & 2.55 & 4-[4-hydroxy-3-(1-methylethyl)benzyl]-3,5- dimethylphenoxy acetic acid ${ }^{15}$ \\
\hline
\end{tabular}


Table S2. Results of the single structure docking under the standard precision.

\begin{tabular}{|l|l|l|l|l|l|}
\hline PDB ID $^{\mathrm{a}}$ & No. actives identified $^{\mathrm{b}}$ & RMSD $^{\mathrm{c}}(\AA)$ & AUC & EF1\% & EF10\% \\
\hline 1N46-nW & 69 & 1.48 & 0.8042 & 26.993 & 6.106 \\
\hline 1NAX-W & 52 & 1.32 & 0.7543 & 23.415 & 5.969 \\
\hline 1NAX-nW & 70 & 1.47 & 0.7834 & 21.889 & 6.295 \\
\hline 1Q4X-W & 92 & 1.21 & 0.8639 & 32.410 & 7.180 \\
\hline 1Q4X-nW & 99 & 1.38 & 0.8080 & 29.393 & 5.561 \\
\hline 1R6G-nW & 94 & 1.59 & 0.7883 & 17.295 & 4.688 \\
\hline 1XZX-W & 72 & 1.21 & 0.7962 & 22.654 & 6.048 \\
\hline 1XZX-nW & 63 & 1.29 & 0.7582 & 16.841 & 5.287 \\
\hline 2J4A-W & 60 & 1.43 & 0.8078 & 27.050 & 6.345 \\
\hline 2J4A-nW & 68 & 1.55 & 0.7769 & 28.221 & 6.353 \\
\hline 3IMY-W & 74 & 1.68 & 0.7884 & 21.177 & 5.690 \\
\hline 3IMY-nW & 83 & 1.79 & 0.7372 & 19.285 & 5.062 \\
\hline
\end{tabular}

${ }^{a}$ PBD ID-W/-nW refers to the docking structure model with/without co-crystallized water (see Materials and Methods for details); ${ }^{b}$ The total number of active THR binders identified by the given single structure model; ${ }^{\mathrm{c}}$ The root-mean-squared-deviation between docking poses and co-crystalized poses of the co-ligands found in each X-ray structure. 
Table S3. Results of the best ensemble model for each given number of structures incorporated.

\begin{tabular}{|l|l|l|}
\hline No. structures & Ensemble of structures $^{\mathrm{a}}$ & No. $^{\text {actives identified }}$ \\
\hline 2 & 1N46-nW, 1R6G-nW & 88 \\
\hline 3 & 1N46-nW, 1R6G-nW, 1XZX-nW & 92 \\
\hline 4 & 1N46-nW, 1Q4X-nW, 1R6G-nW, 1XZX-nW & 95 \\
\hline 5 & 1N46-nW, 1Q4X-nW, 1R6G-nW, 1XZX-nW, 3IMY-W & 96 \\
\hline 12 & All & 96 \\
\hline
\end{tabular}

aPDB ID with "-W" or "-nW" refer to including or excluding crystal waters in the ligand binding site of the PDB structure, respectively; ${ }^{b}$ The total number of active THR binders identified by each ensemble model. 
Table S4. Results of the single best structure docking, the 'best' ensemble model docking, and the MM-GBSA rescoring of the 'best' ensemble model. ${ }^{16}$

\begin{tabular}{|l|l|l|l|l|}
\hline Model ID $^{\mathrm{a}}$ & No. actives identified $^{\mathrm{b}}$ & AUC & EF1\% & EF10\% \\
\hline ssDock (1Q4X-W) & 75 Top 20\%) $^{\mathrm{c}}$ & 0.8639 & 32.410 & 7.180 \\
\hline esDock & 95 & 0.8043 & 25.358 & 6.109 \\
\hline esDock with MM-GBSA & 95 & 0.8647 & 19.018 & 7.478 \\
\hline
\end{tabular}

${ }^{a}$ ssDock, esDock, esDock with MM-GBSA refer to the docking results using 1Q4X and its crystal waters, the docking results of the selected 'best' ensemble model, and the MM-GBSA rescoring results of the selected 'best' ensemble model, respectively; ' ${ }^{\mathrm{b}}$ The total number of active THR binders identified by each docking model; ${ }^{\mathrm{c}}$ For $1 \mathrm{Q} 4 \mathrm{X}-\mathrm{W}$, the docking result was based on the top $20 \%$ of the single structure docking results. 
Table S5. Interactions of the refined hits with the four hydrophilic residues of THR $\beta 1$.

\begin{tabular}{|c|c|c|c|}
\hline Chemical Name & CAS No. & Classification $^{a}$ & $\begin{array}{l}\text { Interaction with } \\
\text { the four } \\
\text { hydrophilic } \\
\text { residues }\end{array}$ \\
\hline 2,4-Dichlorophenoxyacetic acid & $94-75-7$ & $\mathrm{X}-\mathrm{Ph}$ acid & $\begin{array}{l}\text { Arg282-HAccep } \\
\text { Arg320-HAccep } \\
\text { Asn331-HAccep } \\
\text { Arg320-Salt }\end{array}$ \\
\hline 2,4,5-Trichlorophenoxyacetic acid & $93-76-5$ & $\mathrm{X}-\mathrm{Ph}$ acid & $\begin{array}{l}\text { Arg282-HAccep } \\
\text { Arg320-HAccep } \\
\text { Asn331-HAccep } \\
\text { Arg320-Salt }\end{array}$ \\
\hline $\begin{array}{l}\text { 1-((2,4- } \\
\text { dichlorophenyl)carbamoyl)cyclopropanecarboxylic } \\
\text { acid (Cyclanilide) }\end{array}$ & $113136-77-9$ & $\mathrm{X}-\mathrm{Ph}$ acid & $\begin{array}{l}\text { Arg282-HAccep } \\
\text { Arg282-Salt } \\
\text { Arg320-Salt }\end{array}$ \\
\hline Perfluorotetradecanoic acid & $376-06-7$ & PFAS & $\begin{array}{l}\text { Arg282-HAccep } \\
\text { Arg282-HAccep } \\
\text { Arg320-HAccep } \\
\text { Arg282-Salt } \\
\text { Arg320-Salt }\end{array}$ \\
\hline Perfluoroundecanoic acid & $2058-94-8$ & PFAS & $\begin{array}{l}\text { Arg282-HAccep } \\
\text { Arg282-HAccep } \\
\text { Arg320-HAccep } \\
\text { Asn331-HAccep } \\
\text { Arg320-Salt }\end{array}$ \\
\hline Perfluorodecane phosphonate & $52299-26-0$ & PFAS & $\begin{array}{l}\text { Arg282-HAccep } \\
\text { Arg320-HAccep } \\
\text { Asn331-HAccep } \\
\text { Arg282-Salt } \\
\text { Arg320-Salt }\end{array}$ \\
\hline Perfluorooctane sulfonate & $1763-23-1$ & PFAS & $\begin{array}{l}\text { Arg320-HAccep } \\
\text { Arg320-HAccep } \\
\text { Arg320-Salt } \\
\text { Arg282-HAccep }\end{array}$ \\
\hline Perfluorooctane phosphonate & $70887-88-6$ & PFAS & $\begin{array}{l}\text { Arg320-HAccep } \\
\text { Asn331-HAccep } \\
\text { Asn331-HAccep } \\
\text { Arg320-Salt }\end{array}$ \\
\hline Perfluorononanoic acid & $375-95-1$ & PFAS & $\begin{array}{l}\text { Asn331-HAccep } \\
\text { Arg282-HAccep } \\
\text { Arg282-Salt } \\
\text { Arg320-Salt }\end{array}$ \\
\hline Perfluoroheptanoic acid & $375-85-9$ & PFAS & $\begin{array}{l}\text { Arg320-HAccep } \\
\text { Arg320-HAccep } \\
\text { Asn331-HAccep }\end{array}$ \\
\hline Perfluorodecanesulfonate & $335-77-3$ & PFAS & $\begin{array}{l}\text { Asn331-HAccep } \\
\text { Arg282-HAccep }\end{array}$ \\
\hline
\end{tabular}




\begin{tabular}{|c|c|c|c|}
\hline & & & Arg282-Salt \\
\hline Perfluorododecanoic acid & $307-55-1$ & PFAS & $\begin{array}{l}\text { Arg282-HAccep } \\
\text { Arg282-Salt }\end{array}$ \\
\hline 8:2 Fluorotelomer unsaturated carboxylic acid & $70887-84-2$ & PFAS & $\begin{array}{l}\text { Arg320-HAccep } \\
\text { Asn331-HAccep }\end{array}$ \\
\hline Bisphenol A bis(2,3-dihydroxypropyl) ether & $5581-32-8$ & $\mathrm{OH} / \mathrm{X}$ Aromatic & $\begin{array}{l}\text { Asn331-HAccep } \\
\text { Arg320-HAccep } \\
\text { Arg320-HAccep }\end{array}$ \\
\hline $\begin{array}{l}\text { Bisphenol A (3-chloro-2-hydroxypropyl) } \\
\text { dihydroxypropyl) ether }\end{array}$ & $227947-06-0$ & $\mathrm{OH} / \mathrm{X}$ Aromatic & $\begin{array}{l}\text { Asn331-HAccep } \\
\text { Arg320-HAccep } \\
\text { Arg320-HAccep }\end{array}$ \\
\hline Bisphenol AF & $1478-61-1$ & $\mathrm{OH} / \mathrm{X}$ Aromatic & $\begin{array}{l}\text { Asn331-HAccep } \\
\text { Asn331-HDonor }\end{array}$ \\
\hline Bisphenol A (2,3-dihydroxypropyl) glycidyl ether & $76002-91-0$ & $\mathrm{OH} / \mathrm{X}$ Aromatic & $\begin{array}{l}\text { Arg320-HAccep } \\
\text { Arg282-HAccep }\end{array}$ \\
\hline Bisphenol Z & $843-55-0$ & $\mathrm{OH} / \mathrm{X}$ Aromatic & His435-HDonor \\
\hline Bisphenol A & $80-05-7$ & $\mathrm{OH} / \mathrm{X}$ Aromatic & Asn331-HDonor \\
\hline Tetrabromobisphenol A & 79-94-7 & $\mathrm{OH} / \mathrm{X}$ Aromatic & Asn331-HAccep \\
\hline 4,4'-Biphenyldiol & $92-88-6$ & $\mathrm{OH} / \mathrm{X}$ Aromatic & Asn331-HDonor \\
\hline Bisphenol S & $80-09-1$ & $\mathrm{OH} / \mathrm{X}$ Aromatic & Asn331-HDonor \\
\hline 4-Hydroxybenzophenone & $1137-42-4$ & $\mathrm{OH} / \mathrm{X}$ Aromatic & $\begin{array}{l}\text { Asn331-HAccep } \\
\text { Asn331-HDonor }\end{array}$ \\
\hline 2,4,2',4'-Tetrahydroxybenzophenone & $131-55-5$ & $\mathrm{OH} / \mathrm{X}$ Aromatic & $\begin{array}{l}\text { Asn331-HDonor } \\
\text { His435-HDonor }\end{array}$ \\
\hline 4,4'-Methylenediphenol & $620-92-8$ & $\mathrm{OH} / \mathrm{X}$ Aromatic & His435-HDonor \\
\hline Benzyl paraben & $94-18-8$ & $\mathrm{OH} / \mathrm{X}$ Aromatic & Asn331-HDonor \\
\hline 2,4-Dihydroxybenzophenone & $131-56-6$ & $\mathrm{OH} / \mathrm{X}$ Aromatic & Asn331-HDonor \\
\hline Nonylphenol ethoxycarboxylate & $3115-49-9$ & Miscellaneous & $\begin{array}{l}\text { Asn331-HAccep } \\
\text { Arg320-HAccep } \\
\text { Arg282-HAccep } \\
\text { Arg282-Salt } \\
\text { Arg320-Salt }\end{array}$ \\
\hline Carbaryl & $63-25-2$ & Miscellaneous & $\begin{array}{l}\text { Arg320-HAccep } \\
\text { Asn331-HAccep }\end{array}$ \\
\hline Musk ketone & $81-14-1$ & Miscellaneous & Asn331-HAccep \\
\hline Musk moskene & $116-66-5$ & Miscellaneous & Asn331-HAccep \\
\hline
\end{tabular}

${ }^{a} \mathrm{X}-\mathrm{Ph}$ acid, PFASs, and $\mathrm{OH} / \mathrm{X}$ Aromatic refer to halogenated phenoxyacetic acids, per- and polyfluoroalkyl substances, and hydroxylated and/or halogenated aromatic compounds, respectively; ${ }^{b}$ Interactions with the four hydrophilic residues refers to the number of electrostatic interactions with the four key hydrophilic residues (Arg282, Arg320, Asn331, and His435). HDonor, HAccep, and Salt refer to hydrogen bond donor, hydrogen bond acceptor, and salt bridge, respectively. 
Table S6. Information of the dust contaminants tested using the isothermal titration calorimetry (ITC).

\begin{tabular}{|c|c|c|c|c|}
\hline Compounds (Abbreviations) & CAS No. & $\mathrm{pKa}^{\mathrm{a}}$ & Purity & Provider \\
\hline Triiodothyronine (T3) & $6893-02-3$ & 2.13 & $98 \%$ & $\begin{array}{l}\text { Sigma-Aldrich Sweden AB } \\
\text { (Stockholm, Sweden) }\end{array}$ \\
\hline 2,4,5-Trichlorophenoxyacetic acid $(2,4,5-\mathrm{T})$ & $93-76-5$ & 2.88 & $95 \%$ & $\begin{array}{l}\text { Sigma-Aldrich Sweden AB } \\
\text { (Stockholm, Sweden) }\end{array}$ \\
\hline $\begin{array}{l}\text { Bisphenol A (3-chloro-2-hydroxypropyl) } \\
\text { (2,3-dihydroxypropyl) ether (BADGE-HCl- } \\
\text { H2O) }\end{array}$ & $227947-06-0$ & 13.13 & $95 \%$ & $\begin{array}{l}\text { Sigma-Aldrich Sweden AB } \\
\text { (Stockholm, Sweden) }\end{array}$ \\
\hline 2,2',4,4'-Tetrahydroxybenzophenone (BP2) & $131-55-5$ & 6.98 & $97 \%$ & $\begin{array}{l}\text { Sigma-Aldrich Sweden AB } \\
\text { (Stockholm, Sweden) }\end{array}$ \\
\hline 2,4-Dichlorophenoxyacetic acid (2,4-D) & $94-75-7$ & 2.98 & $97 \%$ & $\begin{array}{l}\text { Sigma-Aldrich Sweden AB } \\
\text { (Stockholm, Sweden) }\end{array}$ \\
\hline $\begin{array}{l}\text { 1-((2,4- } \\
\text { dichlorophenyl)carbamoyl)cyclopropanecar } \\
\text { boxylic acid (Cyclanilide) }\end{array}$ & $113136-77-9$ & 3.39 & $95 \%$ & $\begin{array}{l}\text { Sigma-Aldrich Sweden AB } \\
\text { (Stockholm, Sweden) }\end{array}$ \\
\hline $\begin{array}{l}\text { 5-Chloro-2-(2,4-dichlorophenoxy)phenol } \\
\text { (Triclosan) }\end{array}$ & $3380-34-5$ & 7.80 & $97 \%$ & $\begin{array}{l}\text { Sigma-Aldrich Sweden AB } \\
\text { (Stockholm, Sweden) }\end{array}$ \\
\hline
\end{tabular}

${ }^{\mathrm{a}} \mathrm{pKa}$ values of the compounds were collected using the SciFinder database ${ }^{17}$. 
Table S7. The docking scores of different stereoisomers forms of BADGE-HCl-H2O.

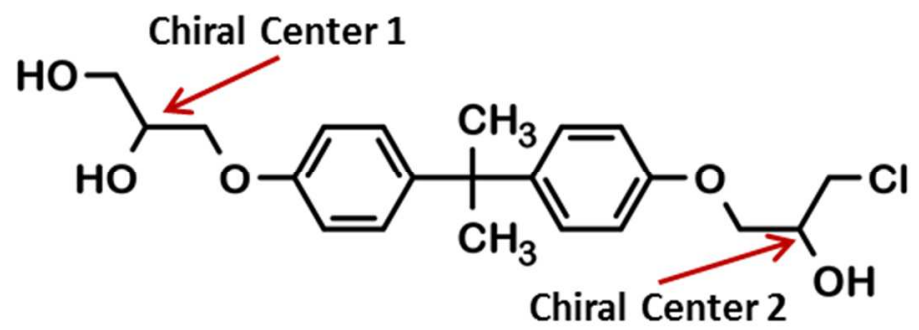

\begin{tabular}{|l|l|l|}
\hline Chiral Center 1 & Chiral Center 2 & Docking Scores \\
\hline R & R & -10.196 \\
\hline R & S & -10.066 \\
\hline S & R & -10.071 \\
\hline S & S & -9.943 \\
\hline
\end{tabular}


Table S8. The energy penalties and docking score of different protonation forms of triclosan.

\begin{tabular}{|l|l|l|}
\hline Protonation State & Energy Penalty $^{\mathrm{a}}(\mathrm{kcal} / \mathrm{mol})$ & Docking Scores \\
\hline Protonated form & 0.3096 & -7.955 \\
\hline Deprotonated form & 0.5326 & -7.578 \\
\hline
\end{tabular}

${ }^{\mathrm{a}}$ The energy penalties of different pronation states were estimated based on the population for each state (P) using the standard thermodynamic relationship, i.e., Penalty $=-\mathrm{RTIn}(\mathrm{P})$. The Schrödinger Epik module ${ }^{18}$ was used to estimate the population of each protonated form. 
Table S9. Thermodynamic parameters of the four active compounds and T3 for binding to THR $\beta 1 .^{\mathrm{a}}$

\begin{tabular}{|l|l|l|l|l|l|l|}
\hline Compounds $^{\mathrm{b}}$ & CAS No. & $\begin{array}{l}\mathrm{K}_{\mathrm{d}} \\
(\mu \mathrm{M})\end{array}$ & $\begin{array}{l}\Delta \mathrm{H} \\
(\mathrm{kcal} / \mathrm{mol})\end{array}$ & $\begin{array}{l}\mathrm{T} \Delta \mathrm{S} \\
(\mathrm{kcal} / \mathrm{mol})\end{array}$ & $\begin{array}{l}\Delta \mathrm{G} \\
(\mathrm{kcal} / \mathrm{mol})\end{array}$ & $\mathrm{N}$ \\
\hline T3 & $6893-02-3$ & $1.6 \pm 0.6$ & $-12.1 \pm 7.9$ & -4.2 & -7.9 & $0.9 \pm 0.2$ \\
\hline 2,4,5-T & $93-76-5$ & $60 \pm 6.6$ & $-3.9 \pm 0.2$ & 1.9 & -5.8 & 1 \\
\hline BADGE-HCl-H2O & $227947-06-0$ & $87.5 \pm 4.9^{\mathrm{c}}$ & $-14.2 \pm 0.9$ & -8.6 & -5.5 & 1 \\
\hline BP2 & $131-55-5$ & $200 \pm 12.5$ & $-5.2 \pm 0.2$ & -0.1 & -5.0 & 1 \\
\hline 2,4-D & $94-75-7$ & $463 \pm 49.3$ & $-3.0 \pm 0.2$ & 1.6 & -4.6 & 1 \\
\hline
\end{tabular}

${ }^{a}$ The full name of the parameters in the table are disassociation constant $\left(\mathrm{K}_{\mathrm{d}}\right)$, enthalpy changes $(\Delta \mathrm{H})$, binding stoichiometry $(\mathrm{N})$, Gibbs free energy changes $(\Delta \mathrm{G})$, and entropy changes $(\Delta \mathrm{S})$; ${ }^{\mathrm{b}}$ The full name of each compound is presented in Table S6; ${ }^{\mathrm{c}}$ For BADGE-HCl-H2O, the dissociation constant was an approximate value mainly due to its poor solubility in the ITC buffer. 
Table S10. Optimized angle force field parameters ${ }^{\mathrm{a}}$.

\begin{tabular}{|l|l|l|l|}
\hline Compound & Angle & $\begin{array}{l}\mathrm{K}_{\theta} \\
\left(\mathrm{kcal} / \mathrm{mol} / \text { radian }^{2}\right)\end{array}$ & $\begin{array}{l}\theta_{0} \\
(\text { degree })\end{array}$ \\
\hline BP2 & C6-C7-C8 & 35.00 & 120.40 \\
\hline BADGE-HCl-H2O & C4-C2-C13 & 99.37 & 109.90 \\
\hline
\end{tabular}

${ }^{\mathrm{a}}$ The angle term in the potential energy function is formulated as $\mathrm{V}=\mathrm{K}_{\theta}\left(\theta-\theta_{0}\right)^{2}$. 
Table S11. Optimized dihedral parameters ${ }^{\mathrm{a}}$.

\begin{tabular}{|l|l|l|l|l|}
\hline Compound & Dihedral angle & $\mathrm{K}_{\chi}(\mathrm{kcal} / \mathrm{mol})$ & $\mathrm{n}$ & $\delta$ (degree) \\
\hline $2,4,5-\mathrm{T}$ & C1-O1-C7-C8 & 1.1000 & 1 & 0.00 \\
\hline $2,4,5-\mathrm{T}$ & C1-O1-C7-C8 & 0.6000 & 3 & 180.00 \\
\hline BP2 & C6-C7-C8-C9 & 0.9600 & 2 & 180.00 \\
\hline BADGE-HCl-H2O & C12-C4-C2-C13 & 0.2300 & 2 & 180.00 \\
\hline BADGE-HCl-H2O & C17-C18-C19-C11 & 1.4000 & 3 & 0.00 \\
\hline BADGE-HCl-H2O & O5-C18-C19-C11 & 1.0000 & 3 & 0.00 \\
\hline BADGE-HCl-H2O & H22-C18-C19-C11 & 0.2000 & 4 & 0.00 \\
\hline
\end{tabular}

${ }^{a}$ The dihedral term in the potential energy function is formulated as $\mathrm{V}=\mathrm{K} \chi[1+\cos (\mathrm{n} \chi-\delta)]$. 
Table S12. Optimized improper angle parameters ${ }^{\mathrm{a}}$.

\begin{tabular}{|l|l|l|l|}
\hline Compound & Improper angle & $\begin{array}{l}\mathrm{K} \psi \\
\left(\mathrm{kcal} / \mathrm{mol} / \mathrm{radian}^{2}\right)\end{array}$ & $\begin{array}{l}\psi_{0} \\
(\text { degree })\end{array}$ \\
\hline BP2 & C6-C7-C8-O1 & 97.0000 & 0.00 \\
\hline
\end{tabular}

${ }^{\mathrm{a}}$ The improper dihedral term in the potential energy function is formulated as $\mathrm{V}=\mathrm{K}_{\psi}\left(\psi-\psi_{0}\right)^{2}$. 


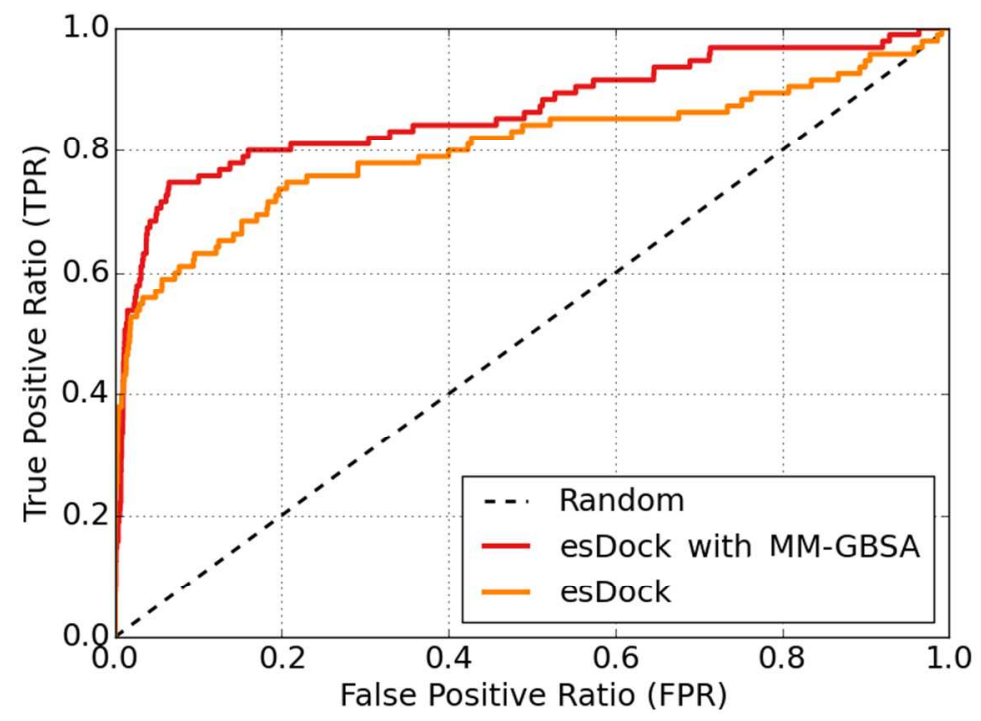

Figure S1. The receiver operating characteristic (ROC) curves of molecular docking and MM-GBSA rescoring results of the 'best' ensemble model. In the ensemble docking, four X-ray structures (i.e., 1N46-nW, 1Q4X-nW, 1R6G-nW, and 1XZX-nW) were selected as the optimal ensemble model in the present structure. "esDock" and "esDock with MM-GBSA" refer to the ROC curves of the selected ensemble docking model and the MMGBSA rescoring results, respectively (See Table S4). 

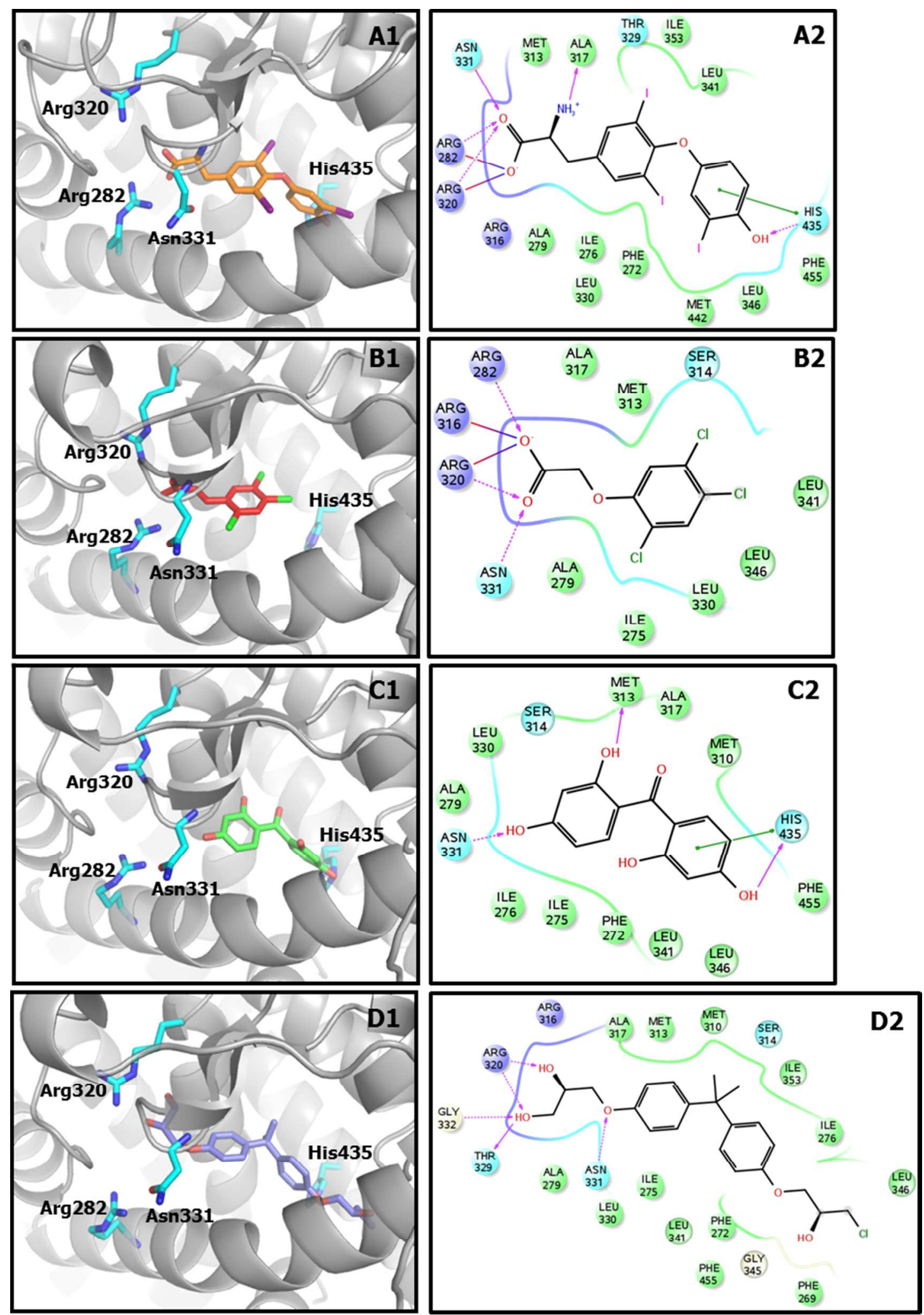

Figure S2. Comparison of docking poses and ligand-THR interactions of potential THR disrupters and cocrystallized pose of T3 (PDB ID: 1XZX). Docking poses: (A1)T3, (B1) 2,4,5-T, (C1) BP2, and (D1) BADGEHCl-H2O. Ligand-THR interactions: (A2)T3, (B2) 2,4,5-T, (C2) BP2, and (D2) BADGE-HC1-H2O. 

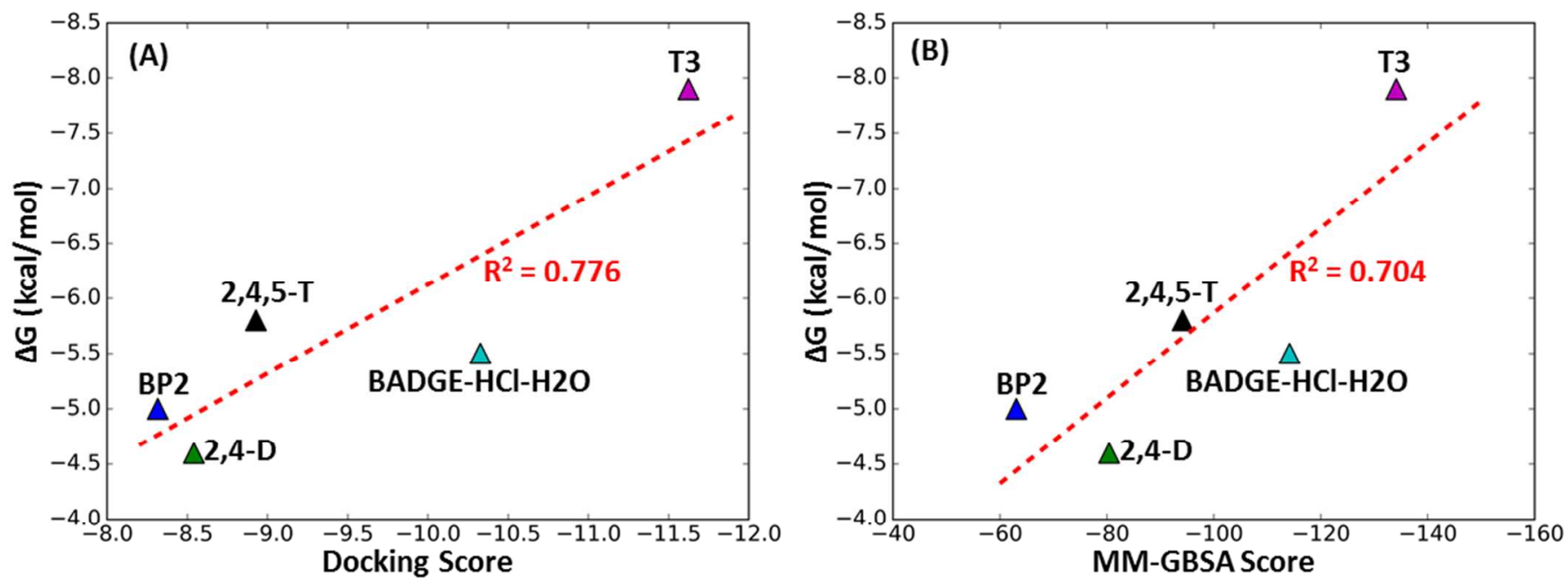

Figure S3. Correlations between ITC measured binding free energy of the bioactive compounds and their (A) docking and (B) MM-GBSA scores. 
(A)

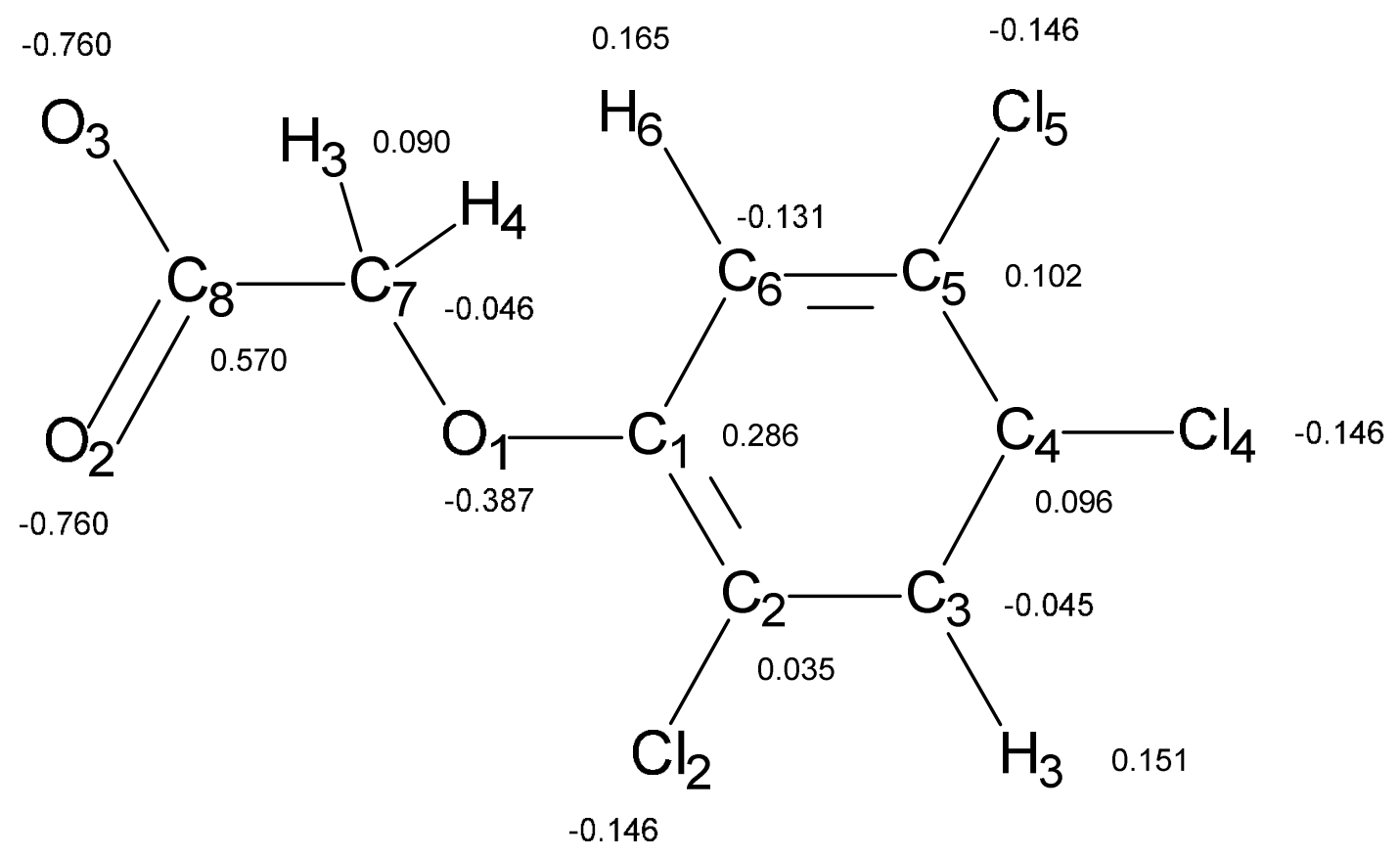

(B)

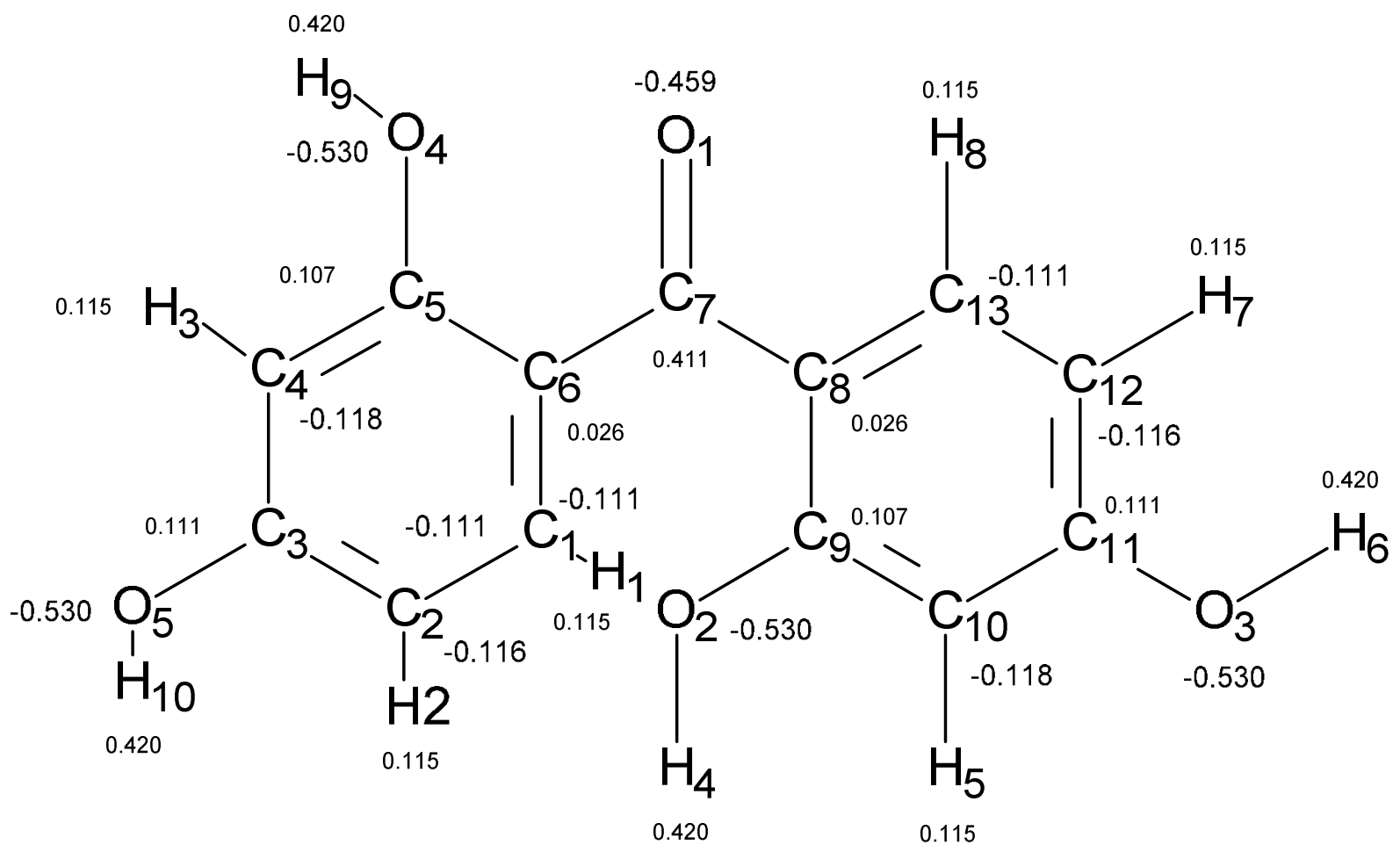


(C)

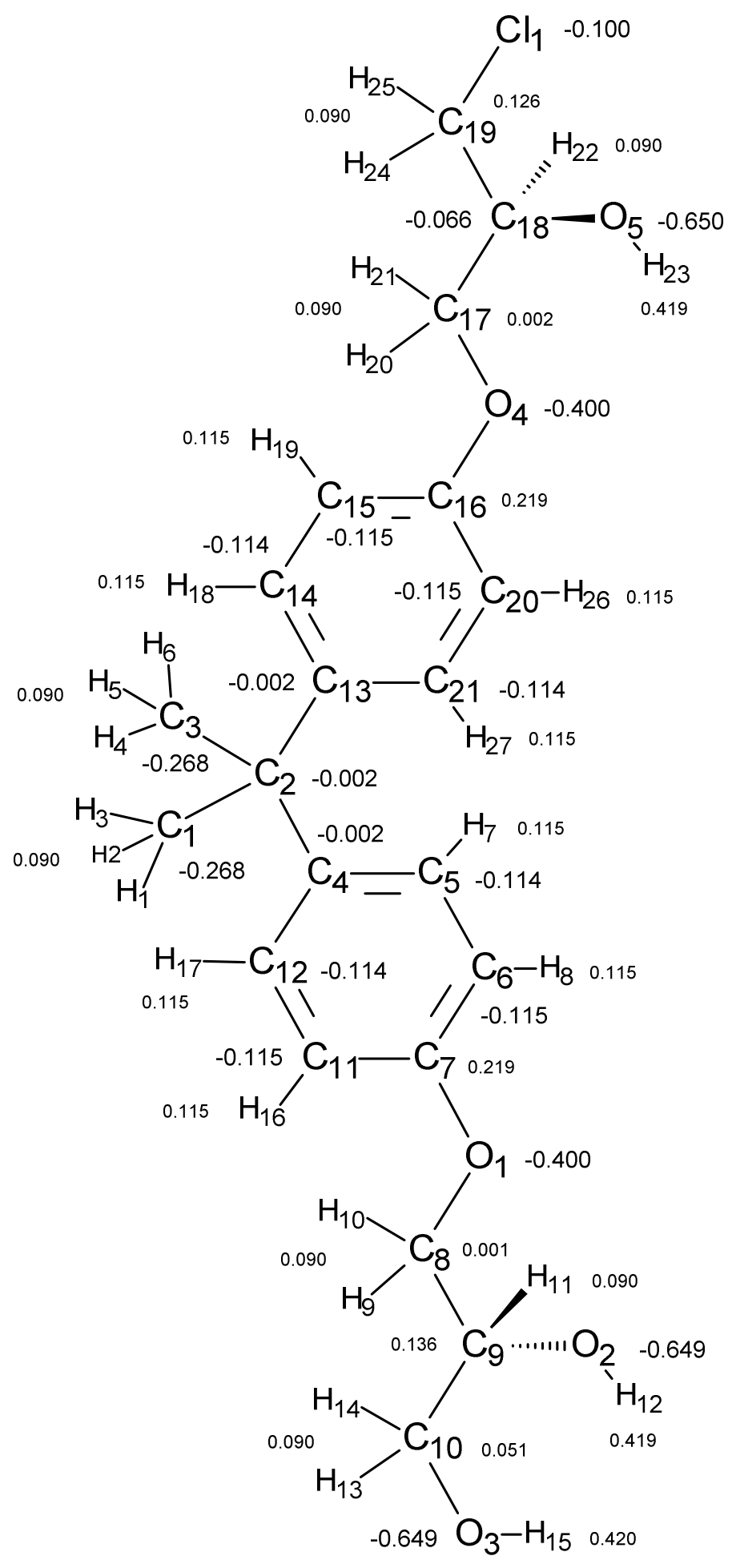

Figure S4. Partial atomic charges of (A) 2,4,5-T, (B) BP2, (C) BADGE-HCl-H2O. For methylene and methyl hydrogens, we only show one value as they share the same charge. 

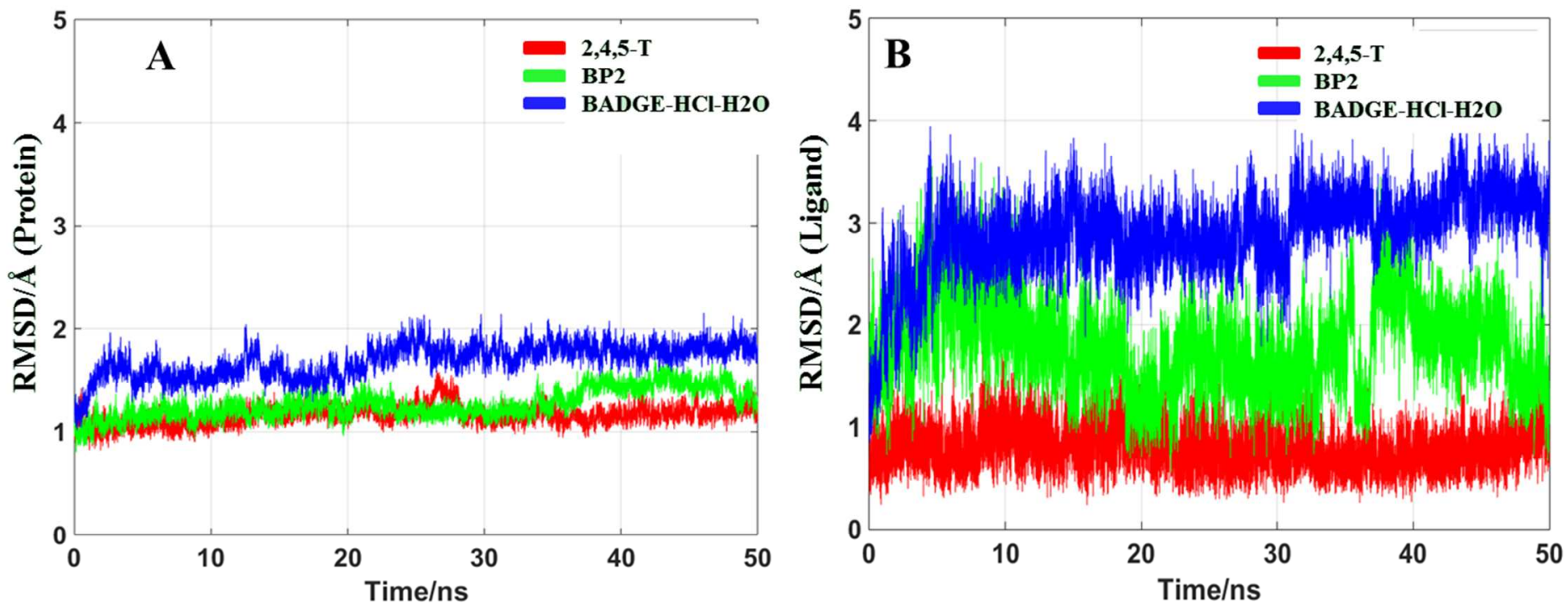

Figure S5. RMSDs of (A) THR $\beta 1$ LBD backbone and (B) the ligands. In the backbone RMSD calculation, only heavy atoms were considered and highly mobile loops (residues 232 to 266,211 to 216,379 to 399 and 410 and 417) were excluded. 


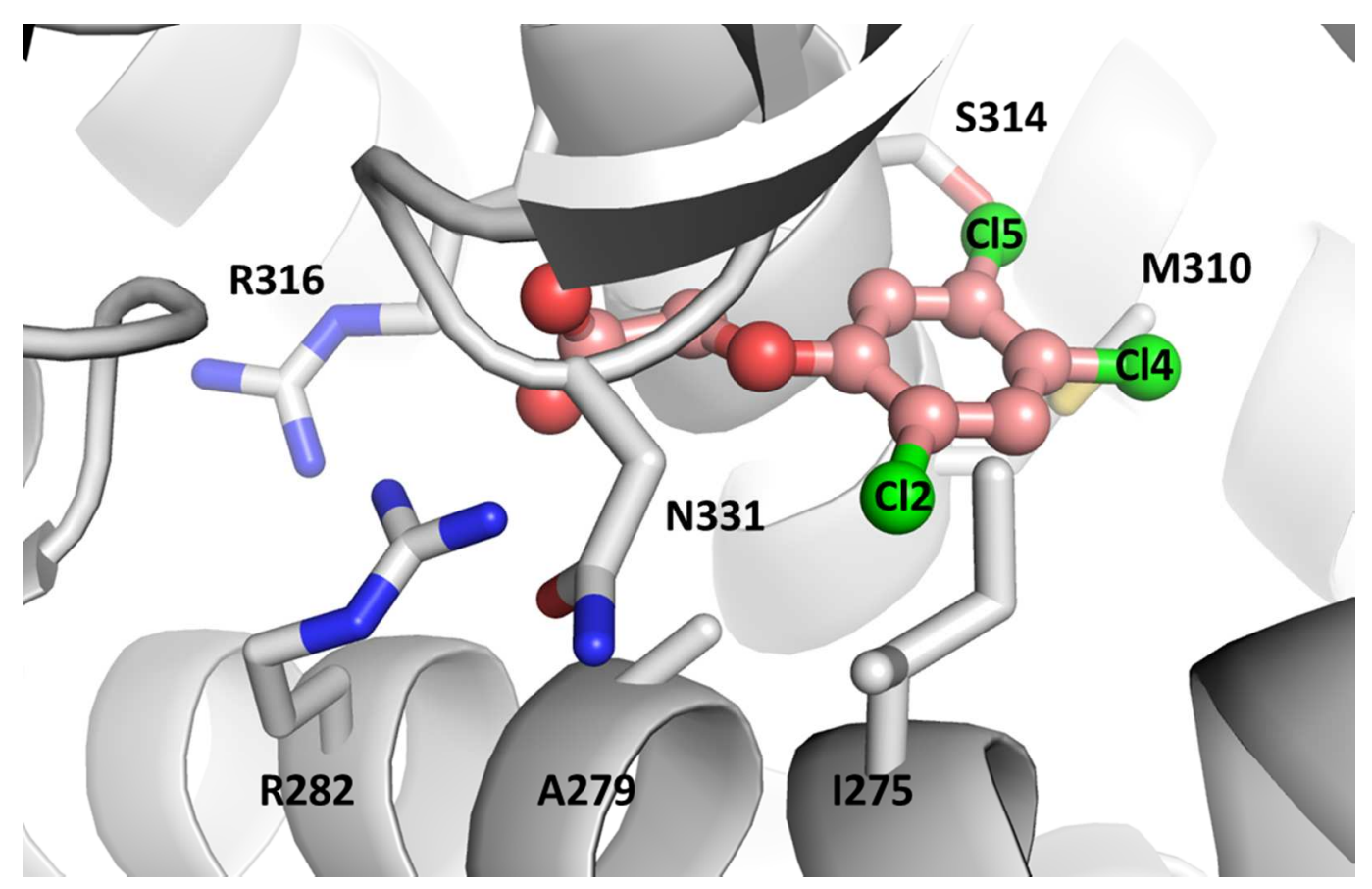

Figure S6. Interactions between 2,4,5-T and THR $\beta 1$ binding pocket residues. Protein backbone and binding pocket residues are shown in gray, and 2,4,5-T is shown in pink, respectively. 

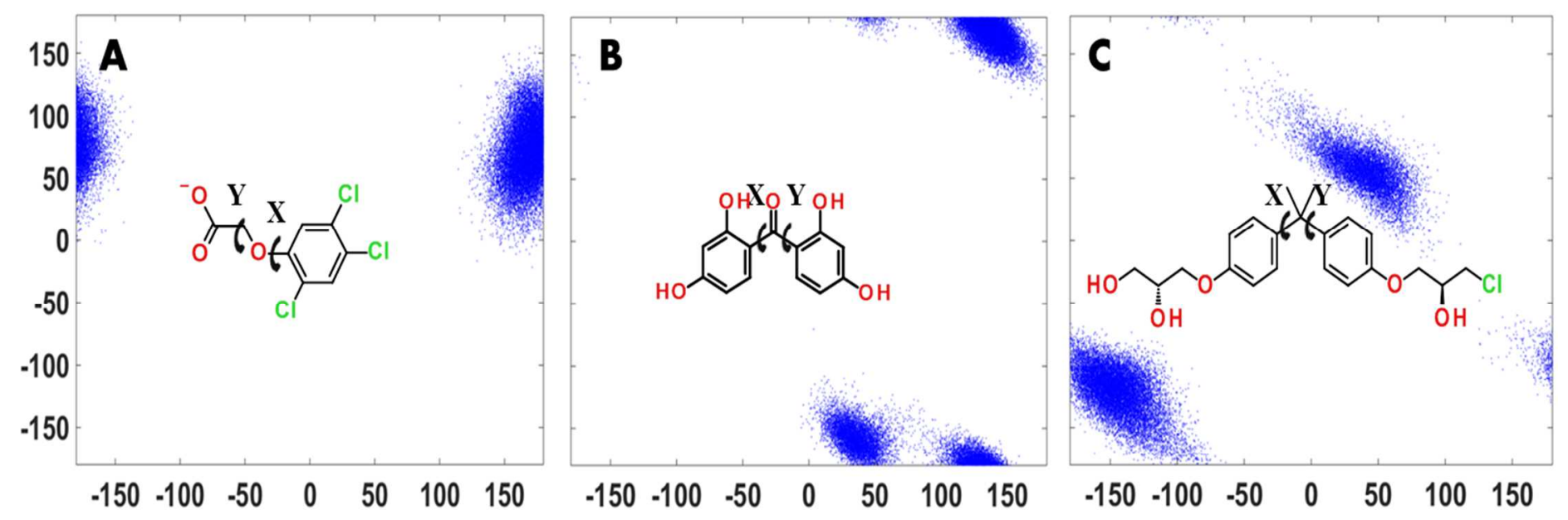

Figure S7. Distributions of the two rotatable dihedral angels for the ligands, (A) 2,4,5-T, (B) BP2, and (C) BADGE-HCl-H2O. To present the variations of the binding poses, two dihedrals on each molecule are chosen, which are indicated by the two arrows on the 2D structures. The dihedral angle along the bond indicated with " $\mathrm{X}$ " is shown in the $\mathrm{X}$-axis, and the angle indicated with " $\mathrm{Y}$ " is shown in the $\mathrm{Y}$-axis of the distribution plot, in which the blue dots show the distributions of these two dihedral pairs. 


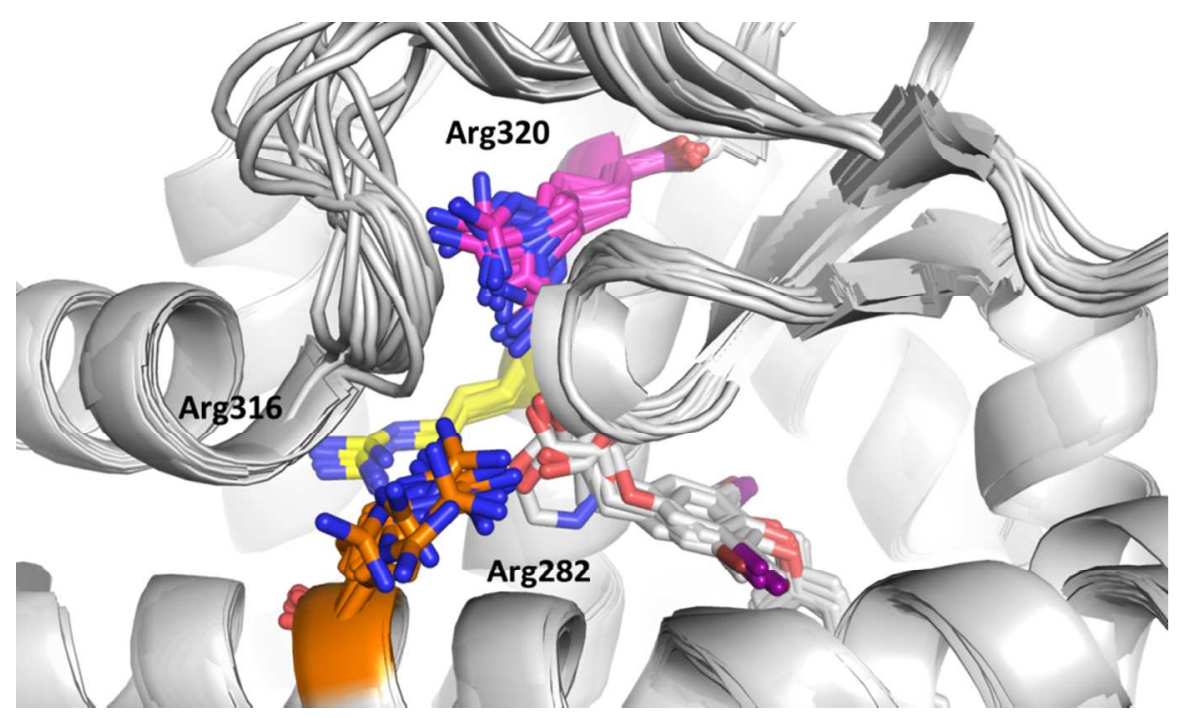

Figure S8. Structural superposition of 15 THR $\beta 1$ LBD crystal structures $\left(1 \mathrm{Q} 4 \mathrm{X}^{11}, 1 \mathrm{~N}^{10} 6^{10}, 2 \mathrm{PIN}^{19}, 2 \mathrm{~J}^{1} \mathrm{~A}^{14}\right.$, $3 \mathrm{IMY}^{15}, 3 \mathrm{JZC}^{5}, 1 \mathrm{BSX}^{20}, 1 \mathrm{XZX}^{13}, 3 \mathrm{GWS}^{21}, 1 \mathrm{NQ}^{22}, 1 \mathrm{R}^{2} \mathrm{G}^{12}, 4 \mathrm{ZO} 1^{23}, 1 \mathrm{NQ} 1^{24}, 1 \mathrm{NAX}^{7}$, and $\left.3 \mathrm{D} 57^{25}\right)$. Arg282, Arg316 and Arg320 are colored in orange, yellow and pink, respectively. Ligands in the binding pocket are shown in stick and proteins are shown in gray cartoon. 


\section{References}

(1) Vanommeslaeghe, K., Hatcher, E., Acharya, C., Kundu, S., Zhong, S., Shim, J., Darian, E., Guvench, O., Lopes, P., Vorobyov, I., and Mackerell, A. D., Jr. (2010) CHARMM general force field: A force field for drug-like molecules compatible with the CHARMM all-atom additive biological force fields. J. Comput. Chem. 31, 671-690.

(2) Vanommeslaeghe, K., and MacKerell, A. D., Jr. (2012) Automation of the CHARMM General Force Field (CGenFF) I: bond perception and atom typing. J. Chem. Inf. Model. 52, 3144-3154.

(3) Breneman, C. M., and Wiberg, K. B. (1990) Determining Atom-Centered Monopoles from Molecular Electrostatic Potentials - the Need for High Sampling Density in Formamide Conformational-Analysis. J. Comput. Chem. 11, 361-373.

(4) Cossi, M., Rega, N., Scalmani, G., and Barone, V. (2003) Energies, structures, and electronic properties of molecules in solution with the C-PCM solvation model. J. Comput. Chem. 24, 669-681.

(5) Martinez, L., Nascimento, A. S., Nunes, F. M., Phillips, K., Aparicio, R., Dias, S. M., Figueira, A. C., Lin, J. H., Nguyen, P., Apriletti, J. W., Neves, F. A., Baxter, J. D., Webb, P., Skaf, M. S., and Polikarpov, I. (2009) Gaining ligand selectivity in thyroid hormone receptors via entropy. Proc. Natl. Acad. Sci. U. S. A. 106, 20717-20722.

(6) Putcha, B. D., and Fernandez, E. J. (2009) Direct interdomain interactions can mediate allosterism in the thyroid receptor. J. Biol. Chem. 284, 22517-22524.

(7) Ye, L., Li, Y. L., Mellstrom, K., Mellin, C., Bladh, L. G., Koehler, K., Garg, N., Garcia Collazo, A. M., Litten, C., Husman, B., Persson, K., Ljunggren, J., Grover, G., Sleph, P. G., George, R., and Malm, J. (2003) Thyroid receptor ligands. 1. Agonist ligands selective for the thyroid receptor beta1. J. Med. Chem. 46, 1580-1588.

(8) Putcha, B. D., Wright, E., Brunzelle, J. S., and Fernandez, E. J. (2012) Structural basis for negative cooperativity within agonist-bound TR:RXR heterodimers. Proc. Natl. Acad. Sci. U. S. A. 109, 6084-6087.

(9) Barkhem, T., Carlsson, B., Simons, J., Moller, B., Berkenstam, A., Gustafsson, J. A., and Nilsson, S. (1991) High level expression of functional full length human thyroid hormone receptor beta 1 in insect cells using a recombinant baculovirus. J. Steroid Biochem. Mol. Biol. 38, 667-675.

(10) Dow, R. L., Schneider, S. R., Paight, E. S., Hank, R. F., Chiang, P., Cornelius, P., Lee, E., Newsome, W. P., Swick, A. G., Spitzer, J., Hargrove, D. M., Patterson, T. A., Pandit, J., Chrunyk, B. A., LeMotte, P. K., Danley, D. E., Rosner, M. H., Ammirati, M. J., Simons, S. P., Schulte, G. K., Tate, B. F., and DaSilva-Jardine, P. (2003) Discovery of a novel series of 6-azauracil-based thyroid hormone receptor ligands: potent, TR beta subtype-selective thyromimetics. Bioorg. Med. Chem. Lett. 13, 379-382.

(11) Borngraeber, S., Budny, M. J., Chiellini, G., Cunha-Lima, S. T., Togashi, M., Webb, P., Baxter, J. D., Scanlan, T. S., and Fletterick, R. J. (2003) Ligand selectivity by seeking hydrophobicity in thyroid hormone receptor. Proc. Natl. Acad. Sci. U. S. A. 100, 15358-15363.

(12) Hangeland, J. J., Doweyko, A. M., Dejneka, T., Friends, T. J., Devasthale, P., Mellstrom, K., Sandberg, J., Grynfarb, M., Sack, J. S., Einspahr, H., Farnegardh, M., Husman, B., Ljunggren, J., Koehler, K., Sheppard, C., Malm, J., and Ryono, D. E. (2004) Thyroid receptor ligands. Part 2: Thyromimetics with improved selectivity for the thyroid hormone receptor beta. Bioorg. Med. Chem. Lett. 14, 3549-3553.

(13) Sandler, B., Webb, P., Apriletti, J. W., Huber, B. R., Togashi, M., Cunha Lima, S. T., Juric, S., Nilsson, S., Wagner, R., Fletterick, R. J., and Baxter, J. D. (2004) Thyroxine-thyroid hormone receptor interactions. J. Biol. Chem. 279, 55801-55808.

(14) Koehler, K., Gordon, S., Brandt, P., Carlsson, B., Backsbro-Saeidi, A., Apelqvist, T., Agback, P., Grover, G. J., Nelson, W., Grynfarb, M., Farnegardh, M., Rehnmark, S., and Malm, J. (2006) Thyroid receptor ligands. 6. A high affinity "direct antagonist" selective for the thyroid hormone receptor. J. Med. Chem. 49, 6635-6637.

(15) Bleicher, L., Aparicio, R., Nunes, F. M., Martinez, L., Gomes Dias, S. M., Figueira, A. C., Santos, M. A., Venturelli, W. H., da Silva, R., Donate, P. M., Neves, F. A., Simeoni, L. A., Baxter, J. D., Webb, P., Skaf, M. S., and Polikarpov, I. (2008) Structural basis of GC-1 selectivity for thyroid hormone receptor isoforms. BMC Struct. Biol. 8, 8 .

(16) Li, J., Abel, R., Zhu, K., Cao, Y., Zhao, S., and Friesner, R. A. (2011) The VSGB 2.0 model: a next generation energy model for high resolution protein structure modeling. Proteins 79, 2794-2812.

(17) Scifinder. (2015) Chemical Abstracts Service. http://www.cas.org/products/scifinder (accessed April 8,2016).

(18) Shelley, J. C., Cholleti, A., Frye, L. L., Greenwood, J. R., Timlin, M. R., and Uchimaya, M. (2007) Epik: a software program for pKa prediction and protonation state generation for drug-like molecules. J. Comput. Aided Mol. Des. $21,681-691$. 
(19) Estebanez-Perpina, E., Arnold, L. A., Jouravel, N., Togashi, M., Blethrow, J., Mar, E., Nguyen, P., Phillips, K. J., Baxter, J. D., Webb, P., Guy, R. K., and Fletterick, R. J. (2007) Structural insight into the mode of action of a direct inhibitor of coregulator binding to the thyroid hormone receptor. Mol. Endocrinol. 21, 2919-2928.

(20) Darimont, B. D., Wagner, R. L., Apriletti, J. W., Stallcup, M. R., Kushner, P. J., Baxter, J. D., Fletterick, R. J., and Yamamoto, K. R. (1998) Structure and specificity of nuclear receptor-coactivator interactions. Genes Dev. 12, 3343-3356.

(21) Nascimento, A. S., Dias, S. M., Nunes, F. M., Aparicio, R., Ambrosio, A. L., Bleicher, L., Figueira, A. C., Santos, M. A., de Oliveira Neto, M., Fischer, H., Togashi, M., Craievich, A. F., Garratt, R. C., Baxter, J. D., Webb, P., and Polikarpov, I. (2006) Structural rearrangements in the thyroid hormone receptor hinge domain and their putative role in the receptor function. J. Mol. Biol. 360, 586-598.

(22) Huber, B. R., Sandler, B., West, B. L., Cunha Lima, S. T., Nguyen, H. T., Apriletti, J. W., Baxter, J. D., and Fletterick, R. J. (2003) Two resistance to thyroid hormone mutants with impaired hormone binding. Mol. Endocrinol. 17, 643-652.

(23) Kojetin, D. J., Matta-Camacho, E., Hughes, T. S., Srinivasan, S., Nwachukwu, J. C., Cavett, V., Nowak, J., Chalmers, M. J., Marciano, D. P., Kamenecka, T. M., Shulman, A. I., Rance, M., Griffin, P. R., Bruning, J. B., and Nettles, K. W. (2015) Structural mechanism for signal transduction in RXR nuclear receptor heterodimers. Nat. Commun. 6, 8013.

(24) Huber, B. R., Desclozeaux, M., West, B. L., Cunha-Lima, S. T., Nguyen, H. T., Baxter, J. D., Ingraham, H. A., and Fletterick, R. J. (2003) Thyroid hormone receptor-beta mutations conferring hormone resistance and reduced corepressor release exhibit decreased stability in the N-terminal ligand-binding domain. Mol. Endocrinol. 17, 107-116.

(25) Jouravel, N., Sablin, E., Togashi, M., Baxter, J. D., Webb, P., and Fletterick, R. J. (2009) Molecular basis for dimer formation of TRbeta variant D355R. Proteins 75, 111-117. 